\title{
To Tell or Not to Tell: \\ The Ethics and Law of Disclosing Health-Related Genetic Information to Family Members
}

\author{
Robert Chapman ${ }^{\mathrm{a}}$, Johanna Devereux , Victoria Nanau, \\ Vanessa Smereczynska ${ }^{a}$, Daria Matsepuro ${ }^{c} \&$ Fatos Selita ${ }^{*}$ \\ a Department of Psychology, Goldsmiths, University of London, UK \\ b Guy's and St Thomas' NHS Foundation Trust, London, UK \\ c Tomsk State University, Tomsk, Russia \\ *Corresponding author. Email: ftselita@gmail.com
}

Background. Genetic conditions and susceptibilities differ from other diseases and health-related risks. Genetic information is shared between blood relatives, and therefore a genetic finding can have implications for the wider family.

Objective. The present study investigates people's views on issues related to disclosing genetic information to relatives. Specifically, the study assesses opinions in relation to two issues: 1) whether people have a moral obligation to share their genetic data with family members; and 2) whether healthcare providers should have a legal obligation to share such data when consent is withheld.

Design. A public engagement event was held based on the real-life court case of $A B C$ vs the UK National Health Service (NHS). Participants were provided with information in three phases: first, about the case; then, with progressively more details of the case; and finally, with other relevant information. After being given each portion of information, the participants were asked to disclose their views on the rights and responsibilities related to the sharing of this information.

Results. The results clearly demonstrate that people hold strong and polarized views regarding confidentiality, and the moral and legal duties to disclose genetic information to family members. Even when withholding information could have an adverse impact on the health and life choices of relatives, participants disagreed about the legal obligations for healthcare providers to disclose a person's genetic information to those relatives.

Conclusion. The results suggest that the issues of privacy and disclosure of genetic information are complex and divisive.

Keywords: Genetics, ethics, public engagement, patient confidentiality, duty of care, data access rights. 


\section{Introduction}

Advances in genetic research and technologies have led to genetic testing being adopted more routinely as part of healthcare treatment in many countries (Botkin et al., 2014). For example, in the UK, the Chief Medical Officer's 2016 report “Generation Genome" focused on the increasing importance of genomics in healthcare treatment and management (Davies, 2017). Most medical conditions have complex genetic etiologies in that they are influenced by many genetic factors (e.g. Balmain, Gray, \& Ponder, 2003). However, some conditions follow relatively simple patterns of inheritance and expression.

Many countries have adopted new-born screening procedures to detect some of these conditions for early intervention and treatment. The number of disorders which are included in new-born screening varies in different countries, from two to more than 20 (Bodamer, Hoffmann, \& Lindner, 2007; Kelly, Makarem, \& Wasserstein, 2016). In the UK, new-born screening is performed for disorders with recognizable latent or early symptomatic stages, and for which prevention programs or treatments are already available.

Based on these criteria, UK screening includes nine congenital disorders: sickle cell disease, cystic fibrosis, congenital hypothyroidism, phenylketonuria (PKU), medium-chain acylCoA dehydrogenase deficiency (MCADD), maple syrup urine disease (MSUD), isovaleric acidaemia (IVA), glutaric aciduria type 1 (GA1), and homocystinuria (pyridoxine unresponsive) (HCU) (NHS, 2018). There are many other single gene disorders for which molecular (genetic) diagnoses are available, but screening for them is not offered population-wide. This is due to the lack of an effective treatment (aside from symptom management) and the rarity of these conditions in the general population without a previous family history of the disease. One such conditions is Huntington's disease (HD; see Figure 1).

\begin{tabular}{|c|c|c|}
\hline 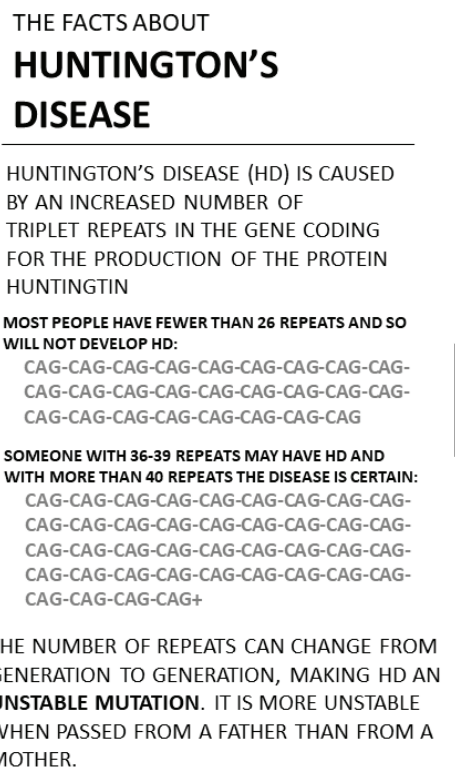 & $\begin{array}{l}\text { CHANCE OF INHERITING HD } \\
\text { HD IS AUTOSOMAL DOMINANT, MEANING } \\
\text { THAT A PERSON NEEDS ONLY } 1 \text { COPY } \\
\text { OF THE DEFECTIVE GENE TO DEVELOP HD } \\
\text { ONSET IS TYPICALLY BETWEEN THE } \\
\text { AGES OF } 30 \text { AND } 50 \text { BUT CAN BE AT } \\
\text { ANY AGE. AGE OF ONSET } \\
\text { AND SEVERITY OF } \\
\text { SYMPTOMS ARE } \\
\text { INFLUENCED BY } \\
\text { GENETIC (60\%) AND } \\
\text { ENVIRONMENTAL } \\
\text { (40\%) FACTORS }\end{array}$ & $\begin{array}{ll}\text { SYMPTOMS INCLUDE: } \\
\checkmark \text { IRRITABILITY } \\
\checkmark \text { DEPRESSION } \\
\checkmark \text { ANXIETY } \\
\checkmark \text { AGGRESSIVE OUTBURSTS } \\
\checkmark \text { MOOD SWINGS } \\
\checkmark \text { SOCIAL WITHDRAWAL } \\
\checkmark \text { POOR COORDINATION } \\
\checkmark \text { INVOLUNTARY MOVEMENTS } \\
\checkmark \text { DIFFICULTIES WITH SPEECH, } \\
\checkmark \text { SWALLOWING, BALANCE, WALKING } \\
\checkmark \text { COGNITIVE DECLINE } \\
\checkmark \text { SHORT-TERM MEMORY LOSS } \\
\checkmark \text { INABILITY TO COPE } \\
\checkmark \text { LACK OF CONCENTRATION } \\
\end{array}$ \\
\hline
\end{tabular}

Figure 1. Information about Huntington's Disease 


\section{Availability of health-related genetic information to blood relatives}

Genetic conditions and susceptibilities differ from other diseases and health-related risks because genetic information is shared among blood relatives. For example, knowing an individual's smoking status is not informative with regards to the health of his or her relatives. By contrast, anything one individual might learn about their personal genetic health risks indicates possible risks for family members, proportionate to the degree of genetic relatedness (e.g. 100\% for identical twins; $50 \%$ for parents, children, or siblings; $25 \%$ for first-degree cousins, aunts and uncles, grand-parents, or half-siblings). This is particularly true for disorders with relatively simple genetic inheritance patterns, like HD (see Figure 1).

In the absence of effective treatments, individuals may find such information either useful or harmful. For example, when considering pre-symptomatic testing for HD, some feel that having a result is important for family planning decisions, while others are concerned about the physical and psychological impact of having such test results (Evers-Kiebooms et al., 2002; van der Steenstraten, Tibben, Roos, van de Kamp, \& Niermeijer, 1994). This presents an ethical and legal dilemma regarding whether such information should be disclosed to family members and by whom.

For individuals this is not currently a legal dilemma, but an ethical one, since there is no law forbidding or forcing individuals to disclose genetic test results to their relatives. However, for medical organizations, the situation is becoming increasingly complicated in this genomic era. Oaths of conduct and ethics are taken by healthcare professionals all over the world (Crawshaw, 1994; Green, 2017; Hulkower, 2016), many of which are based on the Hippocratic oath of the 3rd century CE (Loudon, 1994). The following statements are included in the modern Hippocratic oath:

"I will respect the privacy of my patients, for their problems are not disclosed to me that the world may know," and "I will prevent disease whenever I can, for prevention is preferable to cure."

These two obligations may be difficult to reconcile in the context of genetic information. Consider this example. A woman undergoes a genetic test, which uncovers a BRCA1 gene mutation, which is known to significantly increase the risk of developing breast and ovarian cancer. She opts to undergo a prophylactic double mastectomy surgery and the removal of her ovaries to reduce her risk of developing cancer (Hartmann et al., 2001). The BRCA1 gene is not routinely screened for during healthcare evaluations, but is tested for by women with a known family risk or specific tumor histologies. Therefore, information about the mutation could be important for the woman's sister, who, as a first degree relative, has a 50\% risk of carrying the same mutation.

The woman does not want to disclose the result of her test to her sister. Should the woman's doctor/medical provider respect her confidentiality, in line with the "respect privacy" part of the Hippocratic oath? Or does the provider have an ethical and/or legal obligation to inform the sister, in line with the "prevent disease" aspect of the oath? In other words, should the woman's confidentiality take precedence over the health risk to the sister, or the other way around? 
These questions are no longer hypothetical and have already reached the courts. For example, a case of non-disclosure of HD is currently being decided in the UK courts ( $A B C v$ St George's Healthcare NHS Foundation Trust [2017] EWCA Civ 336, 2017). In this case, action has been brought against the UK National Health Service (NHS) by a patient on the basis that the NHS owed a duty of care to disclose her father's HD diagnosis to her. The daughter asserts that, had she been informed of the risk, and her own diagnosis was confirmed, she would have terminated her pregnancy. The High Court struck her claim on the grounds that there was no reasonably arguable duty of care owed to the daughter by the NHS. The decision of the High Court was appealed by the daughter, and the Court of Appeal reversed the High Court's decision, remitting the case for trial. The differing decisions of the UK courts reflect the complexity of the moral, ethical, and legal issues in such cases.

The increasing use of genetics in medicine, coupled with the relatedness between family members, means that the concepts of medical ethics, consent, and confidentiality need to be revisited. Any such re-evaluation of established social norms should include broad and thorough public discussion. This is especially important when revisions of the social norms could fundamentally change how we conceptualize the "self."

Many ethical and moral dilemmas are difficult to resolve because people hold strong and polarized views on them. These include the issues of abortion, capital punishment, gun ownership, and the age of consent, for which laws also differ across legal systems. Societies now face an additional dilemma: whether or not to disclosue genetic information to family members. People's views on this issue have not been adequately explored.

The present study investigates public opinions about who should have a right to genetic information, and whether this information can be disclosed to relatives without the consent of the person to whom that information relates. In particular, we explore people's views on two questions:

1. Do people have a moral obligation to share their genetic data with family members?

2. Should healthcare providers have a legal obligation to share such data when consent is withheld?

\section{Objectives}

The main aim of our study was to establish whether there is a relative consensus regarding the disclosure of genetic information to family members, or whether opinions relating to this issue are polarized in society. This information is important for updating regulations and developing guidelines for the use of genetic data.

\section{Method}

\section{Participants}

Data were collected from individuals attending a public science engagement event run by The Accessible Genetics Consortium (www.tagc.world) at a university in London in 2018. The event was part of the Genes \& Tonic series, which is dedicated 
to promoting genetic knowledge and its application to different areas, such as education, medicine, and justice. The event was advertised to the public through social media, websites of the university and partner organizations, posters, and word of mouth.

During the event, participants heard talks by a geneticist, a lawyer, and a genetic counsellor, and engaged in activities during which data were collected. Refreshments were provided twice during the event. Data were recorded for 35 participants (22 female) of a median age of 31.88 ( $S D=14.1$, range 18 to 80 ). Fourteen participants had only secondary school education, 10 had completed undergraduate university degrees, and 11 had completed postgraduate studies.

All participants provided written consent for the use of their data in this research. The research was approved by the Goldsmiths University Psychology Department Ethics Committee.

\section{Measures and Procedure}

Upon arrival, participants were provided with a welcome packet and a unique identifier number. This packet contained forms for participants to provide responses to specific questions asked throughout the event, as well as questions to capture demographic information: age, sex, occupation, and highest education level achieved.

Throughout the event, participants were provided with details drawn from the above-mentioned court case (ABC v St George's Healthcare NHS Foundation Trust [2017] EWCA Civ 336, 2017) concerning HD.

Participants were asked to give their opinions three times during the event, as progressively more details about the case, as well as other information, were released to them in successive waves.

At the outset of the evening, participants were provided with background information about the symptoms, progression, and prognosis for HD, and current treatment options. They were also presented with the following overview of the case notes (people's names were altered for the event):

- 2007: Having shot and killed his wife, a man (Fred) was sentenced to a hospital order and a restiction order (related to mental illness). In this connection, his adult children attended family therapy at the same hospital.

- January 2009: Fred's doctors first suspected that he might have HD. They urged him to tell his family; he informed his brother but refused to tell his three daughters.

- 09/02/2009: a diagnosis of HD was confirmed through genetic testing.

- December 2009-January 2010: Healthcare professionals repeatedly urged Fred to disclose his diagnosis to his daughters. Fred withheld consent.

- 08/23/2010: One of his daughters (Claire) was accidentally told by Fred's doctor that her father was diagnosed with HD.

- Late 2010: Claire began the process of suing the NHS for not providing this information officially at the time of diagnosis.

Participants at the event were also advised of the familial risk to Claire and her sisters, i.e. that they each had a 50\% risk of developing HD. The fact that HD can impair cognitive function, and that this might have had an impact on the father's 
ability to understand his and his family's situation, was not emphasized to the participants, although some did comment on this in their feedback. Participants were then asked to give their opinions on a 7 -point scale ( $1=$ not at all to $7=$ definitely) on the following three statements:

1) The patient (daughter) had a right to know about her father's diagnosis.

2) The National Health Service (NHS) should have been legally obliged to provide this information to the daughters.

3) The father had a moral responsibility to provide this information.

Participants were also invited to provide written feedback and comments during each wave of data collection.

The second wave of data collection was preceded by the additional information that the daughter (Claire) was pregnant at the time her father's diagnosis was confirmed. The participants were also informed that she attested that, if she had known of her father's diagnosis, she would have terminated her pregnancy, given her own risk of developing HD and the risk to her unborn child. The participants' opinions were collected again as described above.

The third wave of data collection was preceded by additional information. This time participants were given a hypothetical scenario that a cure for HD had been discovered, but was only effective if begun before symptoms appeared. In this scenario, genetic testing for HD by the NHS was still only available to patients exhibiting symptoms, or to those with a known family history of the disorder. As such, the daughter would only have been able to access the cure if she knew about her father's diagnosis. The participants' opinions were collected for the third time as described previously. It was made clear to them that the scenario was hypothetical (no cure for HD currently exists), but that this is an active area of research.

Participants were asked to record their unique ID on each form they submitted during the evening. Unfortunately, not all participants provided their unique ID on each form they submitted, which led to missing data on some aspects of the analyses (those involving all three waves).

Participants were also asked whether they had ever had a genetic test, if they knew anyone with a genetic condition, or if they had such a condition themselves. They were also asked how influential religion was in informing their opinions and decisions (not at all, somewhat, or greatly influenced) and how confident they were in their genetic knowledge on a scale of 0 (none) to 100 (entirely confident).

\section{Results}

The average participant's confidence in genetic knowledge was relatively low: 36.91 $(\mathrm{SD}=26.27$; range 0 to 85 ). Regarding the influence of religion on their opinions, 31 participants $(88.6 \%)$ reported not being influenced at all; three participants $(8.6 \%)$ reported being influenced to some extent; and one participant (2.9\%) reported strong influence.

As can be seen in Figure 2, there was a general consensus that the father had a moral obligation to provide information to his daughter about his diagnosis. However, opinions were more divided when it came to the daughter's right to such information. Participants' responses were even more polarized when they were asked 
whether the NHS should be legally obliged to disclose genetic information when consent has been withheld. Even following the final wave of information, when participants had been advised that the daughter was pregnant, and that, hypothetically, there was a cure for HD, 22\% of participants still felt that there should be no legal obligation placed on the NHS to disclose the father's diagnosis to the daughter.

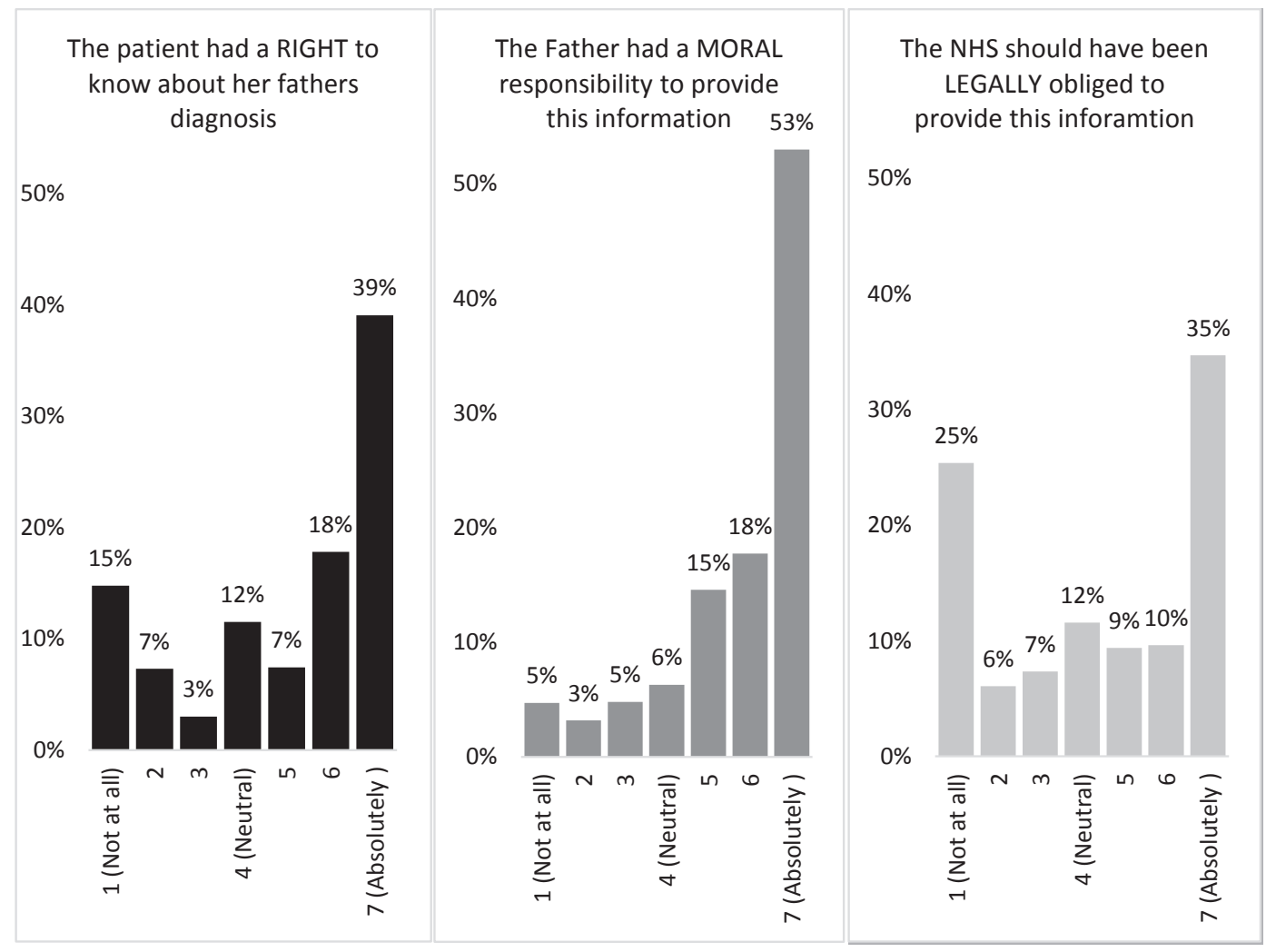

Figure 2. Summed percentage (across the 3 waves) of participants' responses to the 3 statements. Note: Percentage of responses (rather than participant numbers) are reported

As can be seen in Figure 3, participants' opinions remained relatively stable throughout the questioning, with only small increases for each statement across the three waves of data collection.

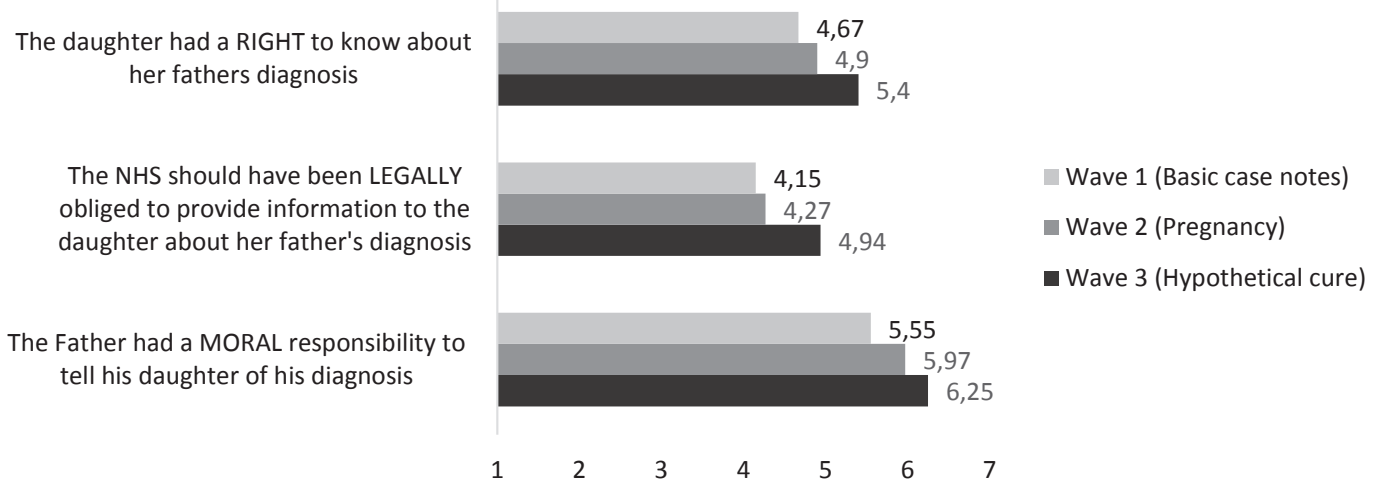

Figure 3. Average score on a scale of 1-7 represented for each wave and each question 
Some potential group differences emerged, although the sample was underpowered to test these statistically. Men tended to be more inclined toward mandating disclosure of the genetic information than women, particularly for the first two questions (Figure 4). Participants who had a genetic condition, either themselves or in their family, were also more inclined towards disclosure (Figure 5). As only four participants ( $11.5 \%$ of the sample) stated that their opinions were influenced by religion to some degree, group analyses of religion are not presented.

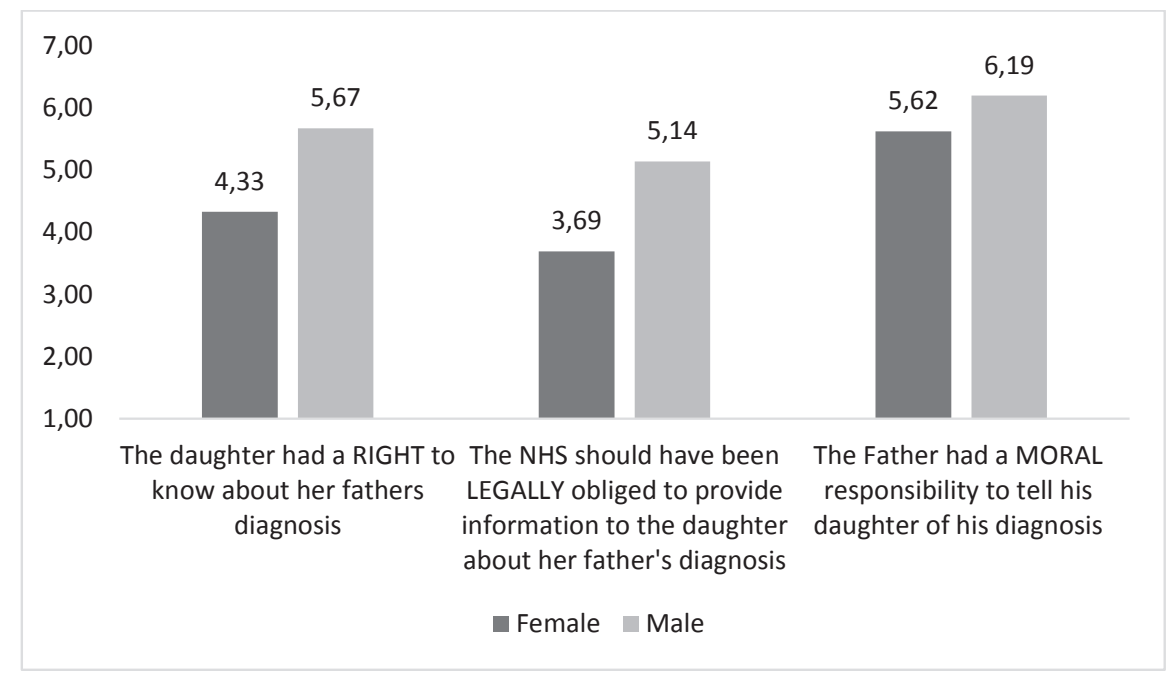

Figure 4. Average score on a scale of $1-7$ for men $(\mathrm{N}=9)$ and women $(\mathrm{N}=13)$ for each question.

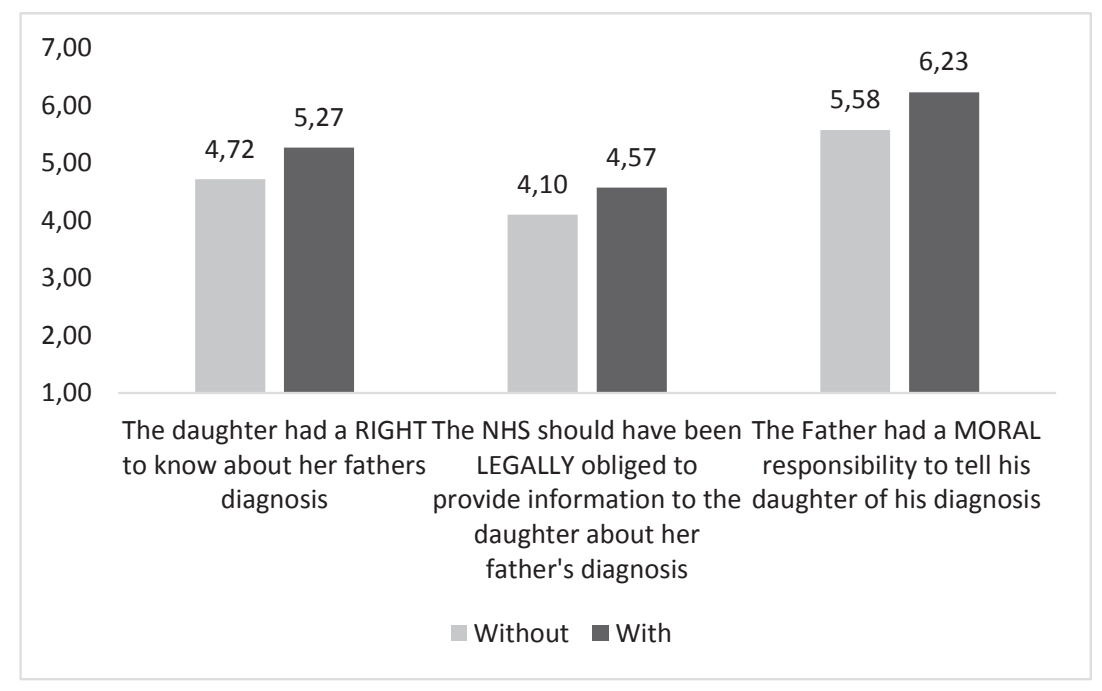

Figure 5. Average score on a scale of $1-7$ for participants without $(\mathrm{N}=17)$ and with $(\mathrm{N}=5)$ a genetic condition, either themselves or in the family.

\section{Qualitative analysis}

The unscripted responses provided by participants clearly demonstrate their strong and polarized views. For example, when in favor of a patient's privacy, participants made such statements as: "If your DNA isn't your own, what is?"; "It remains Fred's 
right alone. Regardless of consequences."; “The NHS were refused permission by the father, a violation of this goes against doctor-patient confidentiality." When in favor of disclosure of the information to the relatives, participants said, for example: "Any information to do with genetics like this must be shared."; "Families need careful genetic counselling to deal with Huntington's. It leads to early death therefore families need to know because of their children." "Fred is now responsible for 2 lives, so is under a lot of moral obligation. It's the woman's choice if she wants to terminate, not Fred. \#Prochoice." The full collection of responses is available from the authors upon request.

\section{Conclusion}

The results of this study demonstrate that people hold strong and polarized views on the issue of confidentiality, and the moral and legal duty to disclose genetic information to family members. In particular, participants disagreed about the legal obligations on healthcare providers to disclose a person's genetic information to relatives, even when withholding information could have adverse impacts on the health, wellbeing, and life choices of those relatives.

Although the study sample size was small, it captured a wide range of ages, professions, and educational backgrounds. Conversely, the sample was also homogeneous in that all participants were interested in genetics, and had intentionally attended a genetic science engagement event. Over half the participants were students, and $60 \%$ had completed degree-level studies, indicating high levels of educational attainment within the sample. The fact that such a diversity of views is present within this sample suggests that the issue of privacy and disclosure of genetic information is complex and divisive.

The results also showed that exposure to the same information, including expert talks on genetics, law, and genetic counselling, did not lead to significantly increased similarity in participants' views. A bigger and more representative study is needed to further explore demographic and other factors that may influence people's views on these matters. For example, the results indicated that having a genetic condition in the family may lead to viewing disclosure of genetic information to family members more favorably.

The case presented in this study is relatively simple, as there is a single known genetic cause for HD. As discussed in the introduction, most diseases have much more complex etiologies, with a mixture of genetic and environmental factors potentially contributing. This etiological complexity makes risk estimates much harder, since genetic information is highly probabilistic. With this increased uncertainty, deciding on ethical and legal responsibility becomes even more complicated. Nevertheless, the need for clarity on these matters is urgent.

However, research shows that societies are unprepared for making informed decisions on updates to laws and policies. For example, a recent study revealed poor genetic literacy among the public when people were presented with multiplechoice questions about simple genetic concepts (Chapman et al., 2018). A lack of knowledge, combined with strong polarized opinions, is a worrying position for society to be in. The present research highlights the need for improved genetic education, but also suggests that simply knowing the facts will not resolve the di- 
lemmas in this area. Further research is needed into the reasons for the strong polarized opinions as a step toward finding optimal solutions. Public engagement will be fundamental to these endeavors.

\section{Limitations}

The data presented here only represent the views of a small number of participants who were already engaged enough with genetics and genomics to attend the event. The numbers were insufficient to allow for meaningful inferential analyses, and this should be addressed in future studies. However, the findings that opinions are polarized and somewhat stable certainly does warrant further investigation.

\section{Acknowledgements}

We are grateful to all the participants for their contribution and to the members of InLab (www.inlab.co.uk) for their support with planning and running the "Genes \& Tonic: Know Thy Father" event. This work was supported by the Russian Ministry for Education and Science (project No. 25.8562.2017/9.10).

\section{References}

ABC v St George's Healthcare NHS Foundation Trust [2017] EWCA Civ 336: Does a doctor owe a duty of care to disclose a hereditary disease to a patient's child? (2017, May 23). Retrieved from https://clinicalnegligence.blog/2017/05/23/abc-v-st-georges-healthcare-nhs-foundation-trust-2017-ewca-civ-336-does-a-doctor-owe-a-duty-of-care-to-disclose-a-hereditarydisease-to-a-patients-child/

Balmain, A., Gray, J., \& Ponder, B. (2003). The genetics and genomics of cancer. Nature Genetics, 33(3s), 238-244. https://doi.org/10.1038/ng1107

Bodamer, O.A., Hoffmann, G.F., \& Lindner, M. (2007). Expanded newborn screening in Europe 2007. Journal of Inherited Metabolic Disease, 30(4), 439-444. https://doi.org/10.1007/ s10545-007-0666-z

Botkin, J.R., Lewis, M.H., Watson, M.S., Swoboda, K.J., Anderson, R., Berry, S. A., ... \& Wilfond, B. (2014). Parental Permission for Pilot Newborn Screening Research: Guidelines from the NBSTRN. Pediatrics, 133(2), e410-e417. https://doi.org/10.1542/peds.2013-2271

Chapman, R., Likhanov, M., Selita, F., Zakharov, I., Smith-Woolley, E., \& Kovas, Y. (2018). New literacy challenge for the twenty-first century: genetic knowledge is poor even among the well-educated. Journal of Community Genetics, 1-12. https://doi.org/10.1007/s12687-0180363-7

Crawshaw, R. (1994). The Hippocratic oath. Is alive and well in North America. BMJ : British Medical Journal, 309(6959), 952.

Davies, S.C. (2017). Annual report of the Chief Medical Officer 2016: generation genome. UK Government. Retrieved from https://assets.publishing.service.gov.uk/government/uploads/ system/uploads/attachment_data/file/631043/CMO_annual_report_generation_genome. pdf

Evers-Kiebooms, G., Nys, K., Harper, P., Zoeteweij, M., Dürr, A., Jacopini, G., ...\& Simpson, S. (2002). Predictive DNA-testing for Huntington's disease and reproductive decision making: a European collaborative study. European Journal of Human Genetics, 10(3), 167-176. https://doi.org/10.1038/sj.ejhg.5200781 
Green, B. (2017). Use of the Hippocratic or other professional oaths in UK medical schools in 2017: practice, perception of benefit and principlism. BMC Research Notes, 10. https://doi. org/10.1186/s13104-017-3114-7

Hartmann, L.C., Sellers, T.A., Schaid, D.J., Frank, T.S., Soderberg, C.L., Sitta, D.L., ...\& Jenkins, R B. (2001). Efficacy of Bilateral Prophylactic Mastectomy in BRCA1 and BRCA2 Gene Mutation Carriers. JNCI: Journal of the National Cancer Institute, 93(21), 1633-1637. https:// doi.org/10.1093/jnci/93.21.1633

Hulkower, R. (2016). The History of the Hippocratic Oath: Outdated, Inauthentic, and Yet Still Relevant. Einstein Journal of Biology and Medicine, 25(1), 41-44. https://doi.org/10.23861/ EJBM20102542

Kelly, N., Makarem, D.C., \& Wasserstein, M.P. (2016). Screening of Newborns for Disorders with High Benefit-Risk Ratios Should Be Mandatory. The Journal of Law, Medicine \& Ethics, 44(2), 231-240. https://doi.org/10.1177/1073110516654133

Loudon, I. (1994). The Hippocratic oath. BMJ (Clinical Research Ed.), 309(6951), 414.

NHS. (2018). Newborn blood spot test - NHS.UK. Retrieved 21 May 2018, from https://www. nhs.uk/conditions/pregnancy-and-baby/newborn-blood-spot-test/

van der Steenstraten, I.M., Tibben, A., Roos, R.A., van de Kamp, J.J., \& Niermeijer, M.F. (1994). Predictive testing for Huntington disease: nonparticipants compared with participants in the Dutch program. American Journal of Human Genetics, 55(4), 618-625.

Original manuscript received July 12, 2018 Revised manuscript accepted September 30, 2018

First published online December 30, 2018 